\title{
Tensile Properties of Dyneema SK76 Single Fibers at Multiple Loading Rates Using a Direct Gripping Method
}

\author{
Brett Sanborn • Ann Mae DiLeonardi • \\ Tusit Weerasooriya
}

Received: 28 October 2014/Accepted: 10 December 2014/Published online: 24 December 2014

(c) Springer Science+Business Media New York 2014

\begin{abstract}
Ultrahigh molecular weight polyethylene (UHMWPE) fibers such as Dyneema and Spectra are seeing more use in lightweight armor applications due to higher tensile strength and lower density compared to aramid fibers such as Kevlar and Twaron. Numerical modeling is used to improve the design of fiber-based composite protective systems. Material response such as tensile stress-strain of different constituents of composites must be studied under experimental conditions similar to strain rates experienced during ballistic events. UHMWPE fibers are difficult to grip by adhesive methods typically used for other fibers due to low surface energy. Based on previous studies, the ability to grip UHMWPE fibers using traditional adhesive methods is dependent on fiber diameter and is limited to smaller diameter fibers which could affect reported stress values. To avoid diameter restrictions and surface energy problems, a direct gripping method has been used to characterize Dyneema SK76 single fibers at quasistatic, intermediate, and high strain rates of $0.001,1$, and $1,000 \mathrm{~s}^{-1}$, respectively. In an effort to understand the effect of defect distribution along a fiber on its tensile response, multiple gage length samples were studied at the different strain rates. In this paper, the dependence of fiber diameter and gage-length on failure strength is discussed as well as success rate of failures in the gage section with this gripping technique. A comparison of the tensile properties to previous studies is also explored in this study.
\end{abstract}

Keywords UHMWPE - Single fiber - Dyneema - SHTB · High rate · Tensile

B. Sanborn $(\bowtie) \cdot$ A. M. DiLeonardi · T. Weerasooriya US Army Research Laboratory, RDRL - WMP - B, Building 4600, Aberdeen Proving Ground, MD 21005, USA

e-mail: brett.sanborn2.ctr@mail.mil

\section{Introduction}

Aramid fibers such as Kevlar and Twaron are frequently used in protective armor, though ultrahigh molecular weight polyethylene (UHMWPE) fibers such as Dyneema and Spectra are more desirable due to lower density $\left(0.97 \mathrm{~g} / \mathrm{cm}^{3}\right)$ compared to aramids $\left(1.44 \mathrm{~g} / \mathrm{cm}^{3}\right)$. UHMWPE fibers also exhibit higher tensile modulus and good resistance to chemical and physical degradation. Due to an increasing need for numerical modeling capability of different soft armor systems, constituent level material properties are required. Furthermore, accurate simulation of impact events requires that material properties be collected under similar loading rate regimes and under valid experimental conditions. The primary loading mode on fibers used in protective equipment is axial tension; therefore, tensile experiments must be conducted at high strain rates that mimic loading rates that are seen in an impact event. UHMWPE fibers such as Dyneema and Spectra are notoriously difficult to grip for these tensile tests due to low surface energy [1], which has been reported by several authors [2, 3].

The ability to grip Dyneema and other UHMWPE fibers using the standard gripping method for fibers which uses an adhesive to attach the fibers to a cardboard substrate is dependent on fiber diameter. Cochron et al. [4] studied Dyneema SK75 single fibers as part of a larger study on a non-woven felt known as Dyneema Fraglight. After imaging fibers in an SEM and finding an average diameter of approximately $8 \mu \mathrm{m}$, the fibers were attached to cardboard substrates via glue and were pulled in tension until failure in an Instron machine. Cochron et al. only completed four experiments, three of which were successful where the fiber was extended until failure in the gage area and did not slip from the glue bond. Hudspeth et al. [5] also reinforces the diameter dependence on adhesive gripping 
Dyneema fibers using adhesives. In their study on the tensile properties of Dyneema SK76 single fiber with preapplied shear strain, Hudspeth et al. successfully used an adhesive method to pull $16 \mu \mathrm{m}$ diameter Dyneema fibers in tension.

Hybrid methods that include adhesives and mechanical gripping have been used by a few authors. Umberger [2] had gripping problems in his study on Spectra fibers that had an average diameter of $27.5 \mu \mathrm{m}$. Umberger settled on an adhesive method that also utilized cardboard mandrels by wrapping approximately $120 \mathrm{~mm}$ of fiber around each mandrel to obtain a $10 \mathrm{~mm}$ sample for tensile testing. Umberger acknowledged that this method was not ideal as there was still slight slippage of the fiber as the fiber tightened around the mandrel as loading commenced. Russell et al. [3] had success performing quasi-static tensile tests on Dyneema SK76 single fibers that were glued to rubber end tabs using cyanoacrylate glue followed by clamping in the serrated jaws of a screw-driven test machine. The authors of that study implied a low success rate using this gripping method and showed a limited number of results.

Gripping methods that do not use adhesives have been used by others. Cansfield et al. [6] studied self-spun UHMWPE fiber at low strain rates using steel clamps and thin sheets of isotropic polyethylene to eliminate damage caused by the clamps. These self-spun UHMWPE fibers had strengths on the order of $0.4-1.2 \mathrm{GPa}$, which are considerably weaker than Dyneema and Spectra fibers that fail at stresses of 2.9-4 GPa depending on the fiber type [7, 8]. Capstan-style grips that are typically utilized in yarn testing have also been used for UHMWPE single fibers [9]. However, the exact gage length of specimens in capstan experiments is difficult to determine which affects ultimate strain and measured modulus values.

Although adhesive-based methods have been shown to be effective for poly (p-phenylene terephthalamide) fibers (PPTA) [10-13], Kim et al. [14-16] have been developing a method of direct gripping on PPTA. This method includes directly clamping the fibers using poly methyl methacrylate (PMMA) blocks. The efficacy of this method to grip Kevlar fibers has been rigorously studied using a variety of statistical methods at different strain rates, including high strain rates which pose additional problems such as minimizing the overall grip size to fit on the Kolsky bar apparatus.

To overcome the difficulties associated with adhesive bonding, hybrid adhesive and mechanical methods, and mechanical methods alone that might not provide accurate strain measurements, a gripping method similar to that used by Kim et al. [14-16] has been used in this study with modifications being made to the grip surface material. With this novel gripping method we were able to collect accurate strain histories of single fiber samples and to load specimens to failure without apparent fiber slippage from the gripping system. Furthermore, this technique is applicable to UHMWPE fibers over a large diameter range and can be utilized at high strain rates. In addition to investigating the loading rate effects on SK76 fibers, a wide range of gage lengths was used to study the effect of defect distribution in the fiber.

\section{Materials}

Single fibers extracted from 1760 dtex Dyneema SK76 yarns were used to study the uniaxial tensile behavior of Dyneema. Several samples were made from single fibers of about $300 \mathrm{~mm}$ in length that were glued to cardboard frames. Due to a high amount of variability in the diameter of Dyneema fiber, individual samples were imaged using an optical microscope with calibrated measuring software to record accurate diameter measurements. For each sample, about 10-20 diameter measurements were taken at different locations along the fiber and were averaged and used as fiber diameter in subsequent stress calculations. While some studies have suggested that UHMWPE fiber lacks roundness and that vibrometry methods are desirable to obtain cross-sectional area measurements [9], Russell et al. [3] showed that Dyneema SK76 single fibers were fairly circular in cross-section. Additionally, vibrometry techniques are limited to samples longer than about $50 \mathrm{~mm}$, which becomes problematic when trying to study the gage length dependence on tensile strength and the high-rate properties of fibers which require much shorter gage length samples [5, 9-13].

In this study, the diameters of 73 single fibers, $300 \mathrm{~mm}$ in length were measured and used to make individual samples. Approximately 40-60 measurements were taken per fiber along the length. Some fibers showed a small variation of $0.296 \mu \mathrm{m}( \pm 1$ standard of deviation) along a $300 \mathrm{~mm}$ length while other fibers had standard of deviations as large as $1.67 \mu \mathrm{m}$ along the length. The median diameter of $300 \mathrm{~mm}$ long fibers used in this study was $18.12 \pm 0.76 \mu \mathrm{m}$.

Since the diameter of the $300 \mathrm{~mm}$ long fibers varied over the length, 10-20 diameter measurements were taken for each individual sample ranging from $5-50 \mathrm{~mm}$ in length for a total of 276 individual fiber samples. These 10-20 measurements were averaged and the average diameter was used in failure stress calculations. The average diameter of all 276 samples was $18.22 \pm 1.15 \mu \mathrm{m}$ while the median diameter was $18.22 \pm 0.46 \mu \mathrm{m}$. The largest diameter sample measured was $22.33 \pm 1.14 \mu \mathrm{m}$ while the smallest diameter fiber sample was $14.53 \pm 0.33 \mu \mathrm{m}$. The median standard deviation in diameter over the collection of fiber 
samples was $0.46 \mu \mathrm{m}$ and the overall average standard deviation was $0.53 \mu \mathrm{m}$.

In an effort to study defect distribution, fibers of multiple gage lengths were studied. Quasi-static and intermediate rate experiments were conducted on specimens with gage lengths of 5,10 , and $50 \mathrm{~mm}$. At high strain rates, specimens with gage lengths of 5,7 , and $10 \mathrm{~mm}$ were studied. Ten experiments were conducted at each gage length and strain rate for a total of 90 experiments.

\section{Experimental Method}

A direct gripping technique for UHMWPE fibers was used in this study as a result of problems associated with directly gluing fiber to cardboard substrates for experimentation. A tensile experiment using a glued fiber is rendered invalid if the fiber slips from the glue bond at any point during extension. A successful adhesive method applied to Dyneema SK76 is dependent upon the diameter of the fiber as noted by Hudspeth et al. who successfully gripped Dyneema fibers of $16 \mu \mathrm{m}$ diameter [5]. Prior to using the direct gripping method described in this study, we handselected fibers under an optical microscope that had a diameter in the range of $14.5-16.9 \mu \mathrm{m}$ and used adhesivebased gripping methods to conduct 36 tensile experiments. None of the fibers from the 36 experiments were extended until failure. Each sample slipped from the glue bond rendering the experiment invalid. Searching through a yarn to identify a fiber that is small enough in diameter for tensile experiments is time consuming especially where the average fiber diameter is on the order of $18.5 \mu \mathrm{m}$. Selecting fibers at random, we measured 276 fiber samples in this study and found that only three had a diameter less than $16 \mu \mathrm{m}$. Based on the results of Hudspeth et al. [5], the upper limit of fiber diameter that may be gripped using adhesive methods alone is $16 \mu \mathrm{m}$, though our results using adhesives suggests that this upper limit rests below a diameter of $14.5 \mu \mathrm{m}$. Based on this, adhesive methods do not work and a direct gripping method is needed to characterize the tensile response of Dyneema SK76.

Using the direct gripping method, single fibers over a wide diameter range are clamped in a fixture that does not allow slipping. Fibers ranging in diameter from $14.5-22.3 \mu \mathrm{m}$ were successfully gripped using this technique. One particularly large fiber sample with diameter of $35.9 \pm 0.52 \mu \mathrm{m}$ was successfully pulled to failure using the direct grip, but was not included in the analysis due to its uncharacteristically large diameter. The specialized clamps used in this study were designed to fit in both a quasi-static/intermediate rate experimental setup and a high-rate fiber-Split Hopkinson Tension Bar (fiber-SHTB) setup. In the grip assembly, a single fiber mounted with cyanoacrylate glue on a cardboard specimen holder is inserted in the grip. The covers of the grip are tightened until the fiber is squeezed with enough force by the polycarbonate clamping blocks such that the fiber will not slip out during the experiment. Repeatability of the applied clamping force was achieved by using a torque setting screwdriver. The cardboard supporting frame is then clipped away and removed by slipping the fiber out of the cyanoacrylate glue joint on the frame. This pulling away of the leftover cardboard frame does not affect the gage area of the fiber that will be pulled in tension once the experiment begins. After removing the cardboard frame, the gage length of the fiber is carefully measured. A simple USB computer-connected Dino-Lite digital camera with $\times 10$ magnification is mounted on stage that translates along the length of the fiber is used to make the gage length measurement. A calibrated dial indicator with a spring-loaded plunger and a $100 \mathrm{~mm}$ measuring range is bolted to the table with the plunger pushing against the stage on which the digital camera is mounted, so that changes in the stage position can measured using the indicator at a resolution of $25 \mu \mathrm{m}$. Crosshairs on the digital camera software are positioned at the interface between the grip and fiber at one end of the fiber specimen and the dial indicator position is set to zero. The camera stage is then repositioned at the opposite end of the fiber specimen with crosshairs positioned at the fiber-grip interface. The length measurement read from the dial indicator is taken to be the fiber gage length.

A side view of the clamped grip and fiber is shown in Fig. 1a. In Fig. 1b, both grips are shown with a fiber spanning between them. The mechanical grips squeeze and deform the fiber to allow gripping to occur. An SEM image of the gripped area of a typical fiber sample is shown in Fig. 2 where the fiber was clamped in the grip and removed for imaging, and was not subjected to mechanical loading. From the images in Fig. 2, the sectional width of the fiber that has been deformed by the grip is noticeably larger than the overall diameter of the non-deformed fiber. The original diameter of this fiber was $18.65 \pm 0.4 \mu \mathrm{m}$, and after gripping, the ends of the fiber that have been squeezed by the grips are deformed to a width of approximately $54 \mu \mathrm{m}$. Using a constant volume assumption to estimate the resulting thickness of the deformed area, the gripped area of the fiber was deformed to a thickness of approximately 5-6 $\mu \mathrm{m}$. If elastic compressibility was accounted for, the gripped thickness could be less than the estimated 5-6 $\mu \mathrm{m}$.

Post failure, the fiber ends tended to recoil and amass at the grips, as shown in Fig. 3. The white arrows in Fig. 3 point to the recoiled fiber ends. Figure 4 shows the same fiber after the failed ends were pulled away from the grip which shows that the fiber failed in the gage area. This failure location was typical of fibers that failed in the gage 

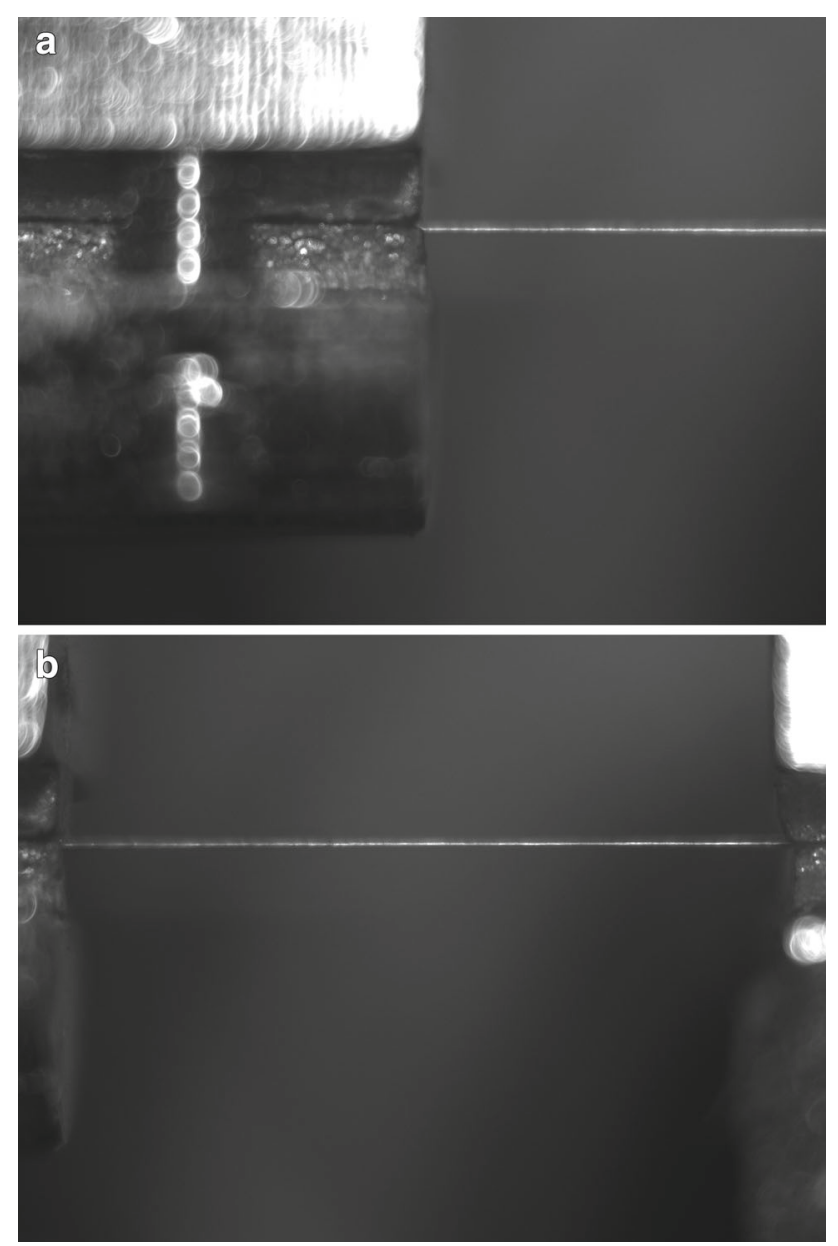

Fig. 1 a Left side of the gripping system. b Gripping system with fiber clamped between the two grips

area, which was a necessary condition to record an experiment as a data point for strength and strain rate behavior analysis. All fibers did not fail in the gage area however, some fibers failed at the grip-fiber interface. The success rate of the gripping method will be discussed in later sections.

\section{Quasi-Static and Intermediate Rate Experiments}

At quasi-static and intermediate rates of to 0.001 and $1 \mathrm{~s}^{-1}$, a Bose ElectroForce TestBench was used to measure the strength. The ElectroForce TestBench is an electromagnetic linear actuator with a maximum force capacity of $200 \mathrm{~N}$. The primary benefits of the ElectroForce are the low noise and vibration levels as compared to a hydraulic load frame. Because the fibers fail at forces on the order of $0.5-1.0 \mathrm{~N}$, sensitive load cells must be used that may be affected by excess vibrations associated with larger hydraulic load frames. The strain $(\varepsilon)$ and strain rate $(\dot{\varepsilon})$ are calculated based on the gage length $\left(l_{s}\right)$ of the sample:
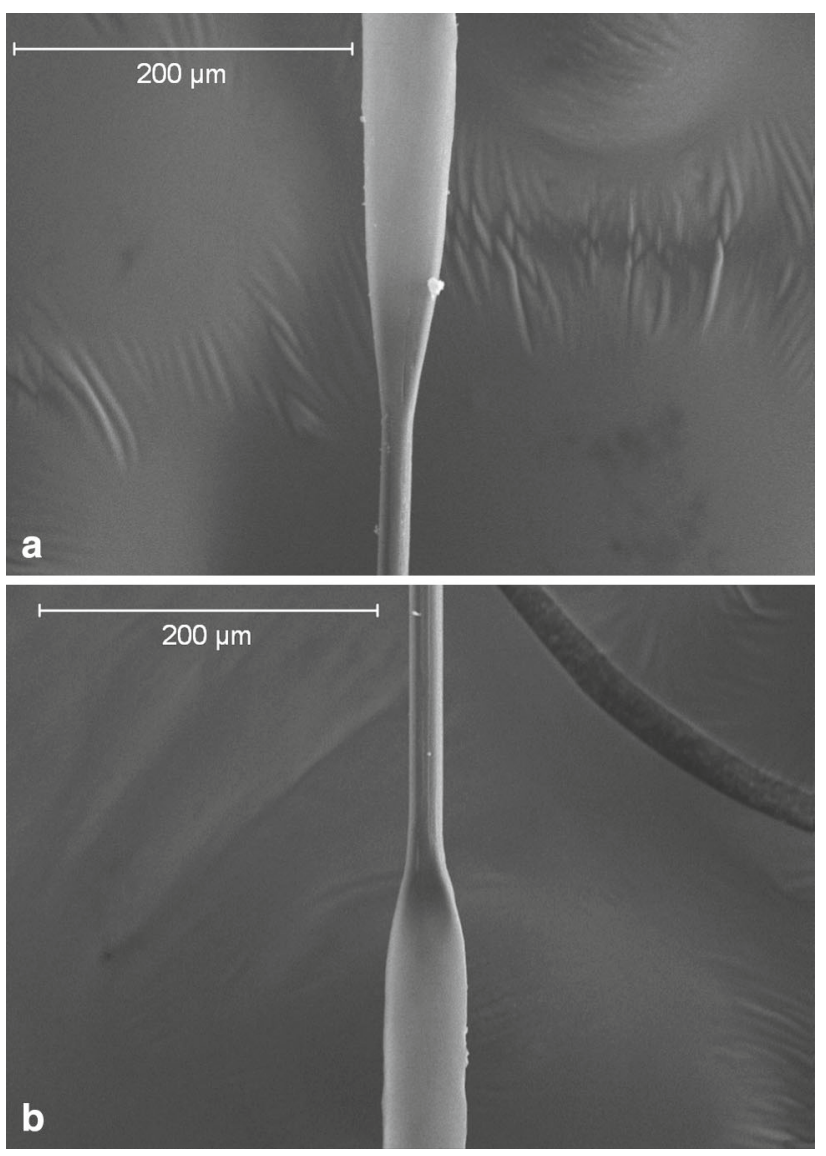

Fig. 2 SEM images of the opposite ends of a fiber sample that has been clamped in the grips and removed for imaging

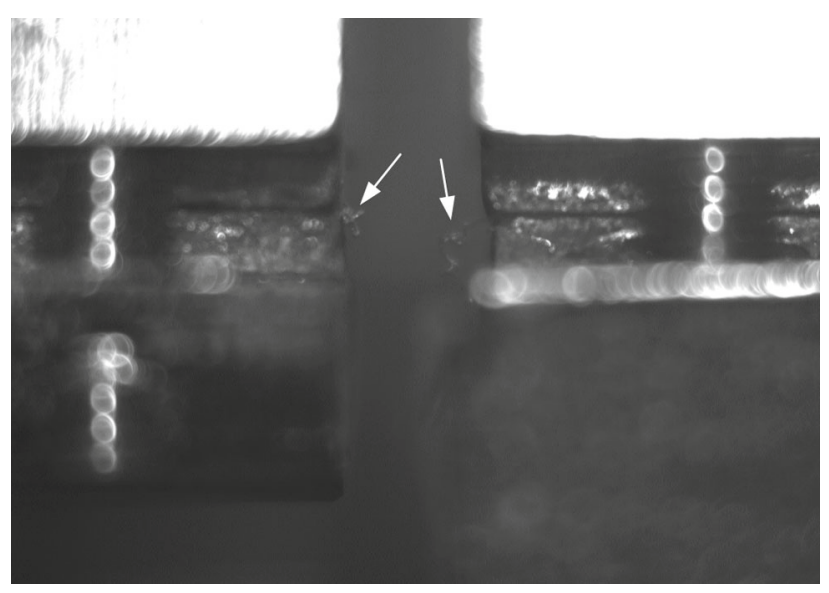

Fig. 3 Fiber ends amassed at the grips following completion of the experiment

$$
\begin{aligned}
& \varepsilon=-\frac{d}{l_{s}}, \\
& \dot{\varepsilon}=-\frac{v}{l_{s}},
\end{aligned}
$$




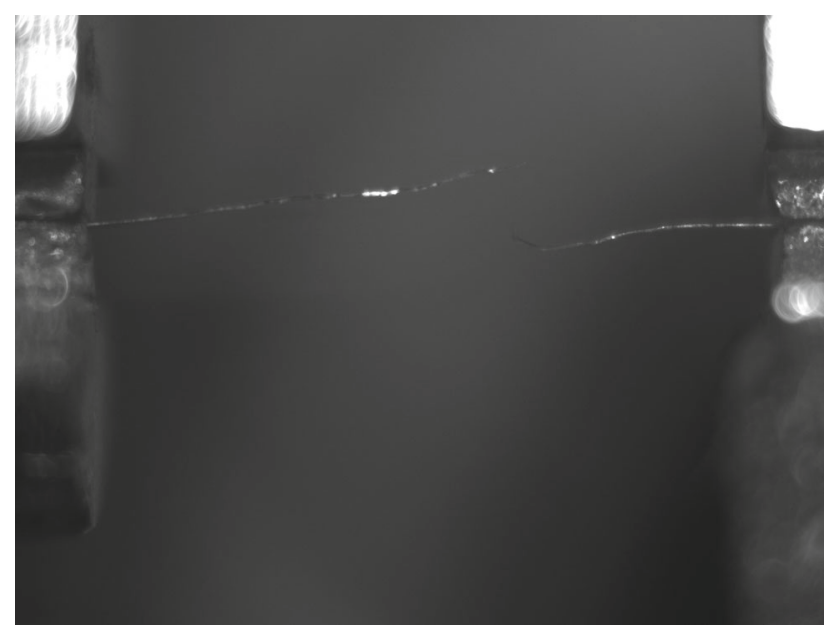

Fig. 4 Failure of a single fiber in the gage area

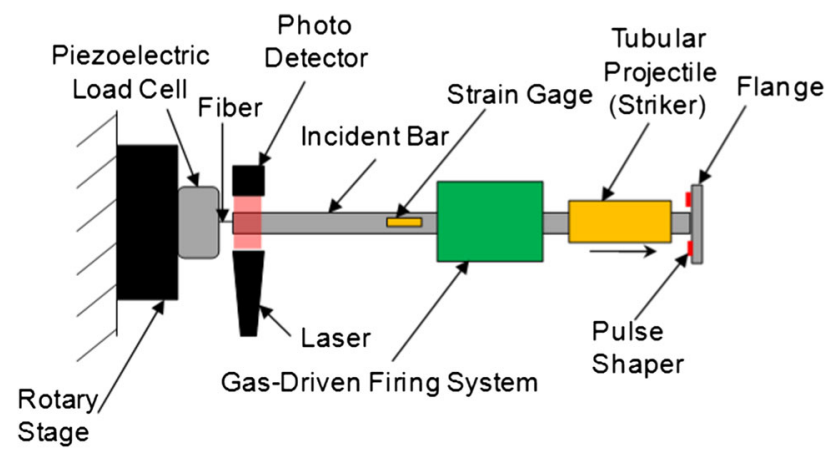

Fig. 5 Schematic of fiber-SHTB

where $d$ is the displacement of the actuator and $v$ is the velocity of the experiment. The specimen stress is calculated using

$\sigma=\frac{P}{A_{0}}$,

where $A_{o}$ is the initial cross-sectional area based upon the diameter measurement obtained using optical microscopy for each sample as discussed in Sect. 2. Finally, $P$ is the force measured by the load cell.

\section{High-Rate Experiments}

The high-rate behavior of the fiber was studied using a fiber-SHTB. A schematic of the fiber-SHTB is shown in Fig. 5. The fiber-SHTB used is similar to the bar used by other authors studying fibers. The fiber-SHTB is similar to traditional SHTBs with the exception that the transmission bar has been replaced by a fast response load cell (Kistler $9712 \mathrm{~B} 5)$ with a high natural frequency $(70 \mathrm{kHz})$ and charge amplifier (5010B) in accordance with past high rate fiber studies $[5,10-13,17]$. The optical strain measurement

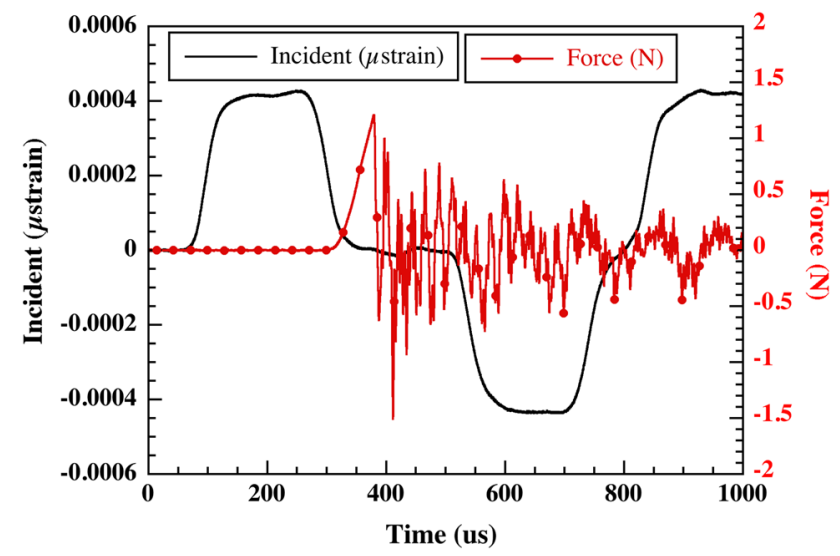

Fig. 6 Raw results from the high strain rate experiment

system used in this study is attributed to Lim et al. [11]. Raw results from a typical high-rate experiment are shown in Fig. 6. A pulse shaper made from copper was used to smooth out initial oscillations in the incident pulse and to vary the rise time. A typical pulse shaper for a $5 \mathrm{~mm}$ gage length fiber experiment was made from $0.1 \mathrm{~mm}$ thick copper tape and $0.18 \mathrm{~mm}$ thick masking tape consisting of nine layers of copper tape and three layers of masking tape.

Equations 1, 2, and 3 are used to obtain strain, strain rate, and stress in the high-rate experiment. The laser-based displacement measurement on the fiber-SHTB is obtained from measuring the end displacement of the incident bar. The linear laser line is created by using a $5 \mathrm{~mW}, 635 \mathrm{~nm}$ wavelength laser passed through a Powell lens. The output voltage is measured using an analogue photo detector (Thorlabs PDA55) located on the opposite side of the incident bar. Prior to the experiment, a relation between displacement and voltage is obtained by uncovering the laser detector in set increments of $50 \mu \mathrm{m}$ and recording the rise in output voltage from the photo detector. It should be noted that the $5 \mathrm{~mW}$ laser used in these experiments (class $3 \mathrm{~A})$ provided enough light to the photo detector to measure bar end displacements. The $100 \mathrm{~mW}$ laser used by Lim et al. [11] (class 3B) is unnecessarily powerful and should be avoided to reduce laser safety requirements in the laboratory.

The strain and stress histories from a high rate fiber experiment are shown in Fig. 7. From the curves in Fig. 7 it is evident that there is no slipping of the fiber from the grips during the experiment, which would be characterized by drops in the load as the fiber is extended as discussed in Sect. 4.1. In this experiment, the fiber failed at a time of approximately $100 \mu$ s. The strain rate history is also obtained by differentiating the laser signal with respect to time, which is shown in Fig. 8. Figure 8 shows that in this experiment, after a ramp time of approximately $60 \mu$ s the fiber deformed at a constant strain rate of $800 \mathrm{~s}^{-1}$ until fracture occurred at approximately $100 \mu \mathrm{s}$. 


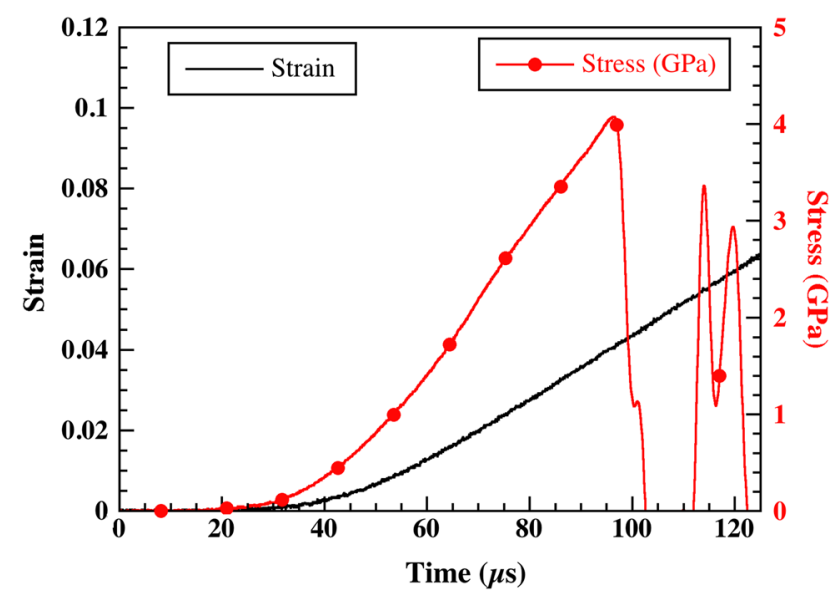

Fig. 7 Stress and strain histories from a high rate experiment

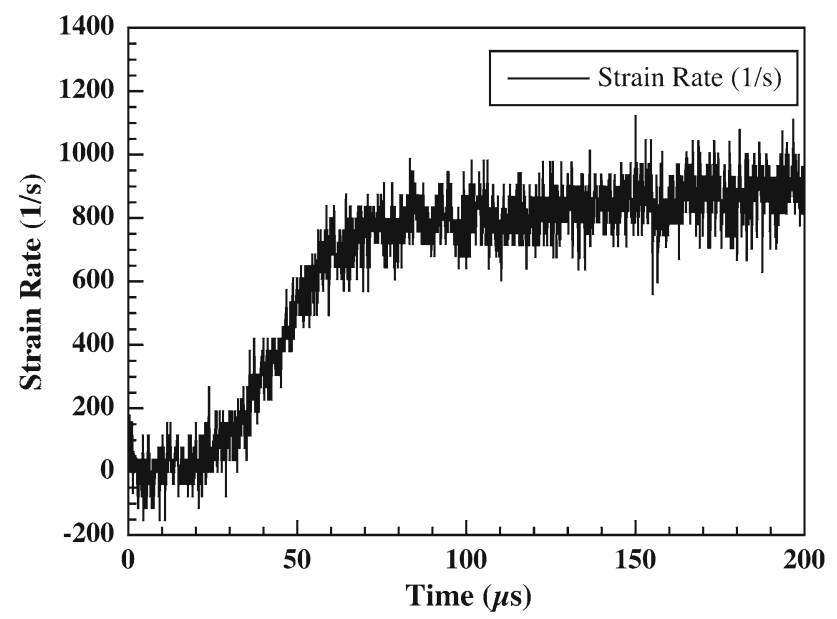

Fig. 8 Strain rate history of an experiment on Dyneema single fiber

\section{Results and Discussion}

\section{Effectiveness of the Direct Gripping Technique}

Overall, the direct gripping technique was successful at multiple gage lengths and strain rates. Representative stress-strain curves from a series of $5 \mathrm{~mm}$ gage length fibers tested at quasi-static strain rate are shown in Fig. 9. The stress-strain behavior in Fig. 9 shows similar behavior to what Russell et al. [3] measured for single fibers though a limited number of results were shown in that study.

The behavior in Fig. 9 shows that fibers did not slip out of the grips during the experiments, which is depicted in Fig. 10. A slipping fiber is characterized by a drop in load as the strain increases followed by either an increase in load or a plateau in load as the strain continues to increase as the fiber slips from the grip or glue. Based on manufacturer values, Dyneema SK76 fiber should fail at approximately $3.3-3.9 \mathrm{GPa}$ at a strain of $3-4 \%$ with a

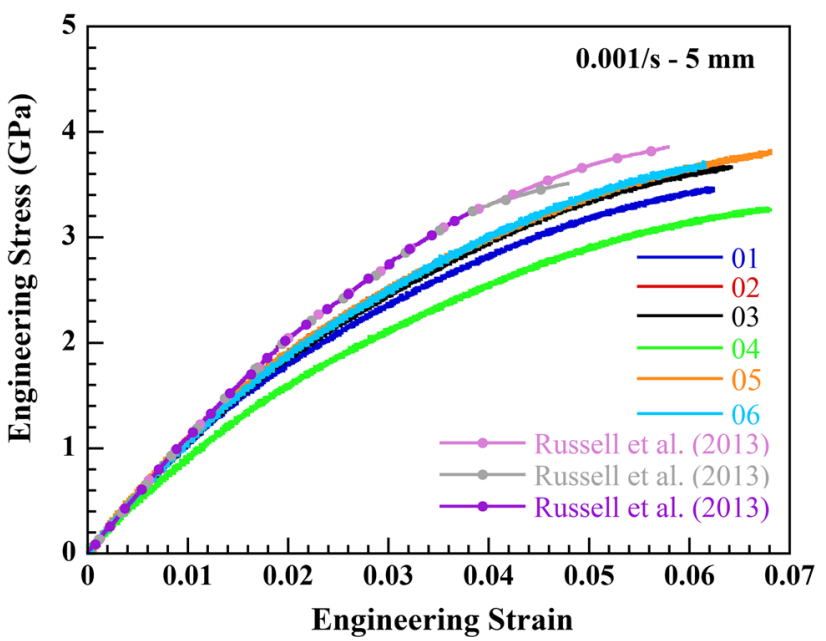

Fig. 9 Typical stress-strain curves from quasi-static experiments including the results of Russell et al. [3] (Color figure online)

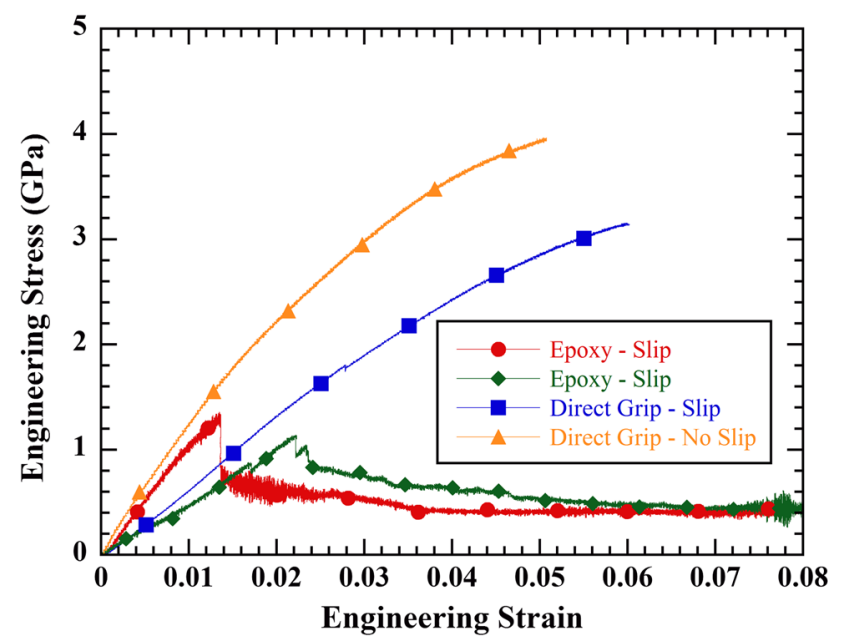

Fig. 10 Examples of fiber slipping using different gripping methods techniques compared to a successfully gripped fiber using the direct grip

Young's modulus of approximately 109-132 GPa at quasistatic strain rates [7]. The curve denoted by filled triangles in Fig. 10 was gripped using the direct gripping method and has a Young's modulus and failure stress that fall within the noted manufacturer values. The failure strain is approximately $0.5 \%$ greater than the noted manufacturer values but is adjusted to account for system compliance as described in a later section. The two experiments where epoxy was used to grip the fiber (filled circles and diamonds) shown in Fig. 10, as is typically used in experimentation on single fibers, show increasing stress with increasing strain until a stress of approximately $1 \mathrm{GPa}$ whereupon a drop in load occurs due to the fiber slipping from the glue bond. As the fiber extension continues, the stress level asymptotes to a value of approximately 
$0.5 \mathrm{GPa}$ at strains greater than what would be expected for this fiber type as the fiber continues to slip through the broken glue bond. In the case of the filled diamond stressstrain curve, the fiber slipped from the glue and bond but was caught again by the epoxy as the stress increases before slipping further and reaching the asymptote of $0.5 \mathrm{GPa}$. This is typical behavior of a slipping fiber.

In terms of modulus, the stress-strain curve denoted by filled circles from an experiment using an epoxy gripping method indicates that the fiber was sufficiently gripped during the initial portion of the experiment prior to slipping because the modulus is approximately $115 \mathrm{GPa}$, which falls within the noted manufacturer values. The stressstrain curve denoted by filled diamonds was also conducted using epoxy to grip the fiber; however, the modulus recorded from this experiment is approximately $50 \mathrm{GPa}$, which is less than half of the manufacturer value and indicates an insufficiently gripped fiber from the beginning of the experiment. The curve denoted by filled squares in Fig. 10 was gripped using the direct gripping technique and indicates that "partial slipping" occurred where the fiber has a lower initial modulus than noted manufacturer values in addition to evidence of a small slip occurring at a strain level of approximately $2.75 \%$. It is worth nothing that this partial slipping eventually results in failure of the fiber specimen unlike the two epoxy experiments where the fiber continued to slip through the broken glue bond. This partial slipping response was only recorded twice during all of the experiments conducted for this study. Because of the unrealistic modulus and failure strain values, these experiments were not included in the data set.

The direct gripping method did not produce fractures or failures in the middle of the gage section $100 \%$ of the time. Different rates of success were experienced for different gage lengths and strain rates. A successful experiment was defined as an experiment where the fiber did not break at the fiber-grip interface or result in the fiber slipping out from the grips as was the case in the filled square stress-strain curve in Fig. 10. The ratio between the number failures in the gage section and the total number of experiments completed to reach a total of ten experiments at each condition of gage length and strain rate is shown in Table 1.

As shown in Table 1, experimental success was higher at quasi-static and intermediate rates compared to high-rate experiments. Therefore, at high loading rates, more experiments must be conducted to obtain enough successful experiments to compare with experiments at lower loading rates. The reason for lower success at high rate is not well understood and is worthy of further investigation. The success rate does not appear to depend on the fiber gage length. Table 2 shows a comparison of failures occurring in the gage section to failures at the grip in terms
Table 1 Success rate of direct gripping method under different experimental conditions

\begin{tabular}{llll}
\hline $\begin{array}{l}\text { Gage length } \\
(\mathrm{mm})\end{array}$ & $\begin{array}{l}\text { Quasi-static } \\
\text { rate }(\%)\end{array}$ & $\begin{array}{l}\text { Intermediate } \\
\text { rate }(\%)\end{array}$ & $\begin{array}{l}\text { High } \\
\text { rate }(\%)\end{array}$ \\
\hline 5 & 83 & 73 & 33 \\
7 & - & - & 28 \\
10 & 90 & 91 & 42 \\
50 & 71 & 83 & - \\
\hline
\end{tabular}

Cells with "-" indicates that experiments were not conducted under those conditions

Table 2 Comparison between failures in-gage-section to failures at the grip at high rate

\begin{tabular}{llll}
\hline $\begin{array}{l}\text { High rate } \\
\text { gage } \\
\text { length } \\
(\mathrm{mm})\end{array}$ & $\begin{array}{l}\text { Failure in } \\
\text { gage area } \\
\text { strength } \\
(\mathrm{GPa})\end{array}$ & $\begin{array}{l}\text { Failure at } \\
\text { fiber-grip } \\
\text { interface } \\
\text { strength }(\mathrm{GPa})\end{array}$ & $\begin{array}{l}\text { Ratio of failure strength } \\
\text { at grip interface to } \\
\text { failure strength in gage } \\
\text { area }(\%)\end{array}$ \\
\hline 5 & $4.24 \pm 0.39$ & $3.86 \pm 0.44$ & 91.1 \\
7 & $4.25 \pm 0.21$ & $3.99 \pm 0.34$ & 93.9 \\
10 & $4.08 \pm 0.17$ & $4.07 \pm 0.30$ & 99.7 \\
\hline
\end{tabular}

of failure strength. In all cases fibers that failed at the grip had a weaker strength than their failed-in-gage-section counterparts. At 5 and $7 \mathrm{~mm}$ gage lengths, the end-break fibers were about 7-9 \% weaker while at $10 \mathrm{~mm}$ the endbreak fibers were less than $1 \%$ weaker than the in-gagesection failures. Previous low rate studies on UHMWPE single fibers bonded directly to cardboard using epoxies show low success rates as low as $10 \%$ [2] on $27.5 \mu \mathrm{m}$ diameter fibers. Prior to the present study using direct gripping, our attempts to study Dyneema SK76 fibers in the 14.5-16.9 $\mu \mathrm{m}$ diameter range using adhesive gripping had a $0 \%$ success rate at all loading rates and gage lengths.

The gripping technique also works well at high rate. Five typical high rate stress-strain curves are shown in Fig. 11, which shows reasonable variation between experiments. There is no evidence of the fiber slipping out from the grips as there are no sudden drops in stress and the recorded modulus values are within the expected range for Dyneema SK76.

\section{Uniaxial Tensile Strength at Multiple Strain Rates}

The strengths from uniaxial tension experiments conducted at various strain rates are shown in Fig. 12 as a function strain rate, and the values \pm one standard of deviation are given in Table 3. In general, there is an increasing relationship between failure strength and strain rate, which has also been noted by other authors for UHMWPE [3, 5, 6, 18, 19]. 


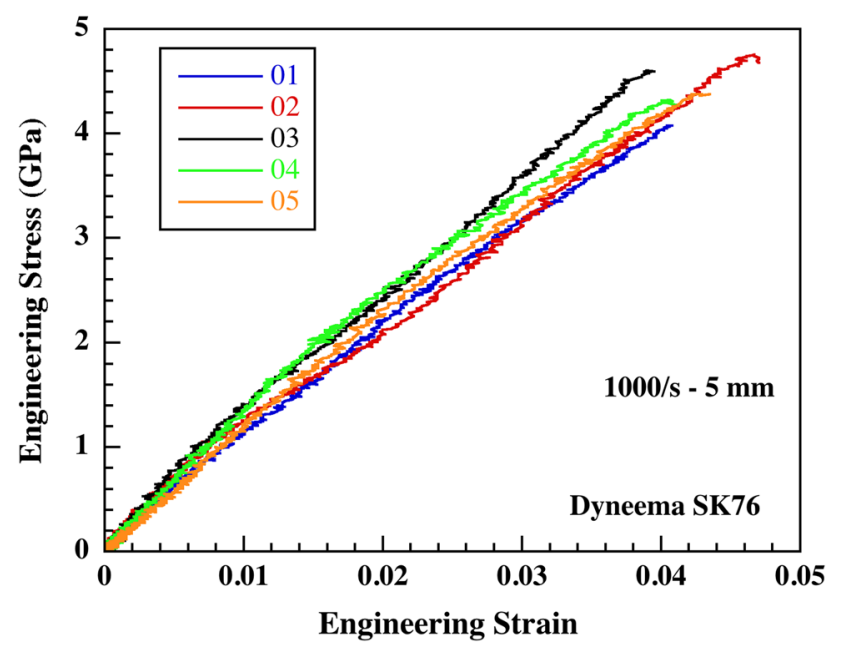

Fig. 11 High-rate stress-strain curves for Dyneema SK76 with approximately $18 \mu \mathrm{m}$ diameter, $5 \mathrm{~mm}$ gage length samples (Color figure online)

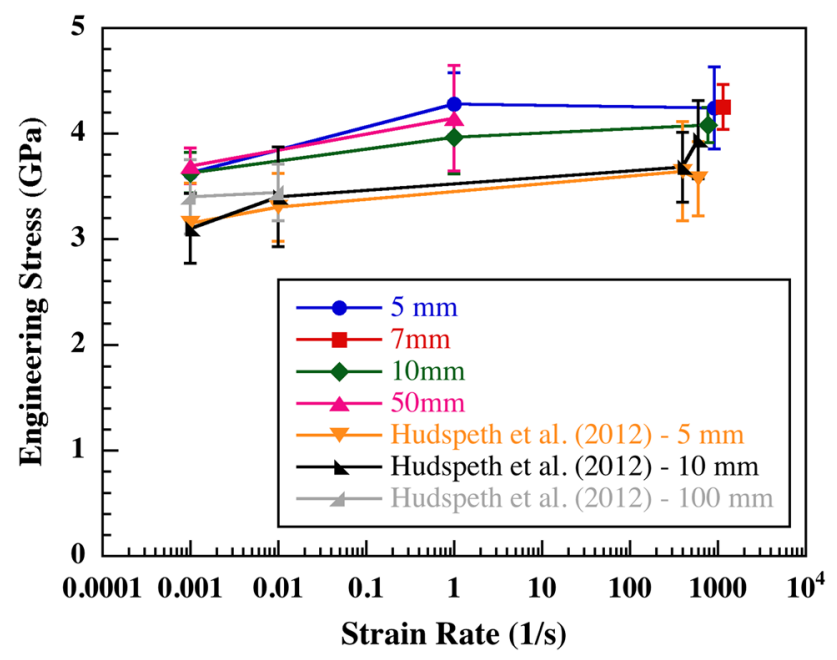

Fig. 12 Effect of strain rate on the tensile strength for different gage lengths including the results of Hudspeth et al. [5]

The present study on Dyneema SK76 found higher strengths compared to the results of Hudspeth et al. [5] on the same fiber type. They found strengths of approximately $3.12-3.15 \mathrm{GPa}$ for 5 and $10 \mathrm{~mm}$ gage lengths at $0.001 \mathrm{~s}^{-1}$, with an increase to approximately $3.31-3.40 \mathrm{GPa}$ at $0.01 \mathrm{~s}^{-1}$, while we measured failure strengths of 3.63-3.69 GPa in the same range of strain rates. At high strain rates, Hudspeth et al. noted strengths of 3.63-3.67 GPa for 5 and $10 \mathrm{~mm}$ gage lengths at $400 \mathrm{~s}^{-1}$, while strengths of 3.56 and $3.92 \mathrm{GPa}$ were measured for 5 and $10 \mathrm{~mm}$ gage length fibers respectively at $600 \mathrm{~s}^{-1}$. At $1,000 \mathrm{~s}^{-1}$, our results show strengths that are 4.08-4.25 GPa, which are notably higher than Hudspeth et al. Furthermore, the strengths from Hudspeth et al. show that long gage length fibers $(100 \mathrm{~mm})$ were stronger than short gage length $(5$ and $10 \mathrm{~mm})$ fibers by about $8 \%$ at $0.001 \mathrm{~s}^{-1}$. The
Table 3 Averaged strengths \pm 1 standard of deviation at different strain rates and gage lengths

\begin{tabular}{lllll}
\hline $\begin{array}{l}\text { Strain } \\
\text { rate }\left(\mathrm{s}^{-1}\right)\end{array}$ & $\begin{array}{l}5 \mathrm{~mm} \\
\text { strength } \\
(\mathrm{GPa})\end{array}$ & $\begin{array}{l}7 \mathrm{~mm} \\
\text { strength } \\
(\mathrm{GPa})\end{array}$ & $\begin{array}{l}10 \mathrm{~mm} \\
\text { strength } \\
(\mathrm{GPa})\end{array}$ & $\begin{array}{l}50 \mathrm{~mm} \\
\text { strength } \\
(\mathrm{GPa})\end{array}$ \\
\hline 0.001 & $3.63 \pm 0.19$ & - & $3.64 \pm 0.31$ & $3.69 \pm 0.17$ \\
1 & $4.28 \pm 0.30$ & - & $3.96 \pm 0.35$ & $4.14 \pm 0.50$ \\
775 & - & - & $4.08 \pm 0.17$ & - \\
913 & $4.24 \pm 0.39$ & - & - & - \\
1,156 & - & $4.25 \pm 0.21$ & - & - \\
\hline
\end{tabular}

results of the present study do not show this difference when comparing the short ( 5 and $10 \mathrm{~mm}$ ) gage length fibers to the $50 \mathrm{~mm}$ gage length fibers. The average failure strength of the 5,10 , and $50 \mathrm{~mm}$ gage length fibers used in this study were $3.63 \pm 0.19,3.64 \pm 0.31$, and $3.69 \pm 0.17 \mathrm{GPa}$, respectively, representing an increased failure strength of only $1.5 \%$ at the longer gage length. Unlike similar studies on Kevlar [10-13] we do not see the fiber strength increasing as the gage length decreases. Further studies on shorter gage length fibers would help probe the presence of any defects and also quantify the spacing of such defects.

The results of failure strength found in this study suggest that Dyneema SK76 reaches a failure strength plateau at strain rates in the intermediate regime $\left(1 \mathrm{~s}^{-1}\right)$ instead of increasing gradually from quasi-static to high-rate as previous studies suggest [5], evidenced by the similarity of the strengths in the range of $1 \mathrm{~s}^{-1}$ and approximately $1,000 \mathrm{~s}^{-1}$. This plateau in strength at intermediate rate is similar to the behavior of Dyneema SK76 yarns observed by Russell et al. [3]. In the study of yarn strength, the ultimate strength of Dyneema yarn reached a plateau just before a strain rate of $1 \mathrm{~s}^{-1}$. In another study on Dyneema SK60 single fibers, tensile strength at different temperatures was examined and related to strain rate and the work to fracture was found to reach a constant value at a strain rate of approximately $1 \mathrm{~s}^{-1}$ [20]. These results suggest that the plateau in failure strength reached at intermediate rate is a behavior independent of the fiber type and is an inherent property of Dyneema fiber. Further studies on the tensile behavior extended to higher strain rates might confirm this finding.

\section{Tensile Failure Strain at Multiple Strain Rates}

The accepted method when conducting experiments on single fibers is that the failure strain must be corrected using the ASTM compliance correction method [10-12, 21], even when experimentation is completed at high strain rates on a fiber-SHTB [11]. Tables of the uncorrected and corrected failure strains using the method outlined in ASTM 1557-03 are shown in Tables 4 and 5, respectively. 
Table 4 Uncorrected failure engineering strains

\begin{tabular}{lllll}
\hline $\begin{array}{l}\text { Strain } \\
\text { rate } \\
\left(\mathrm{s}^{-1}\right)\end{array}$ & $\begin{array}{l}5 \mathrm{~mm} \\
\text { failure } \\
\text { strain }(\%)\end{array}$ & $\begin{array}{l}7 \mathrm{~mm} \\
\text { failure } \\
\text { strain }(\%)\end{array}$ & $\begin{array}{l}10 \mathrm{~mm} \\
\text { failure strain } \\
(\%)\end{array}$ & $\begin{array}{l}50 \mathrm{~mm} \\
\text { failure strain } \\
(\%)\end{array}$ \\
\hline 0.001 & $6.49 \pm 0.43$ & - & $5.53 \pm 0.87$ & $4.30 \pm 0.38$ \\
1 & $5.70 \pm 0.42$ & - & $4.83 \pm 0.72$ & $3.6 \pm 0.28$ \\
775 & - & - & $3.71 \pm 0.26$ & - \\
913 & $4.11 \pm 0.42$ & - & - & - \\
1,156 & - & $4.52 \pm 0.48$ & - & - \\
\hline
\end{tabular}

Table 5 ASTM 1557-03 compliance corrected failure engineering strains

\begin{tabular}{lllll}
\hline $\begin{array}{l}\text { Strain } \\
\text { rate } \\
\left(\mathrm{s}^{-1}\right)\end{array}$ & $\begin{array}{l}5 \mathrm{~mm} \\
\text { failure } \\
\text { strain }(\%)\end{array}$ & $\begin{array}{l}7 \mathrm{~mm} \\
\text { failure } \\
\text { strain }(\%)\end{array}$ & $\begin{array}{l}10 \mathrm{~mm} \\
\text { failure strain } \\
(\%)\end{array}$ & $\begin{array}{l}50 \mathrm{~mm} \\
\text { failure strain } \\
(\%)\end{array}$ \\
\hline 0.001 & $3.48 \pm 0.42$ & - & $3.93 \pm 0.96$ & $3.96 \pm 0.36$ \\
1 & $2.92 \pm 0.23$ & - & $3.35 \pm 0.75$ & $3.29 \pm 0.25$ \\
775 & - & - & $3.00 \pm 0.24$ & - \\
913 & $2.58 \pm 0.31$ & - & - & - \\
1,156 & - & $3.51 \pm 0.57$ & - & - \\
\hline
\end{tabular}

After the compliance correction is applied, the range of failure strain of the SK76 fiber becomes 2.58-3.96\%, which is close to the value of 3-4\% for similar fiber types (SK75 and SK78) as noted by the manufacturer [7], which gives greater confidence of the application of the direct gripping method applied to UHMWPE fibers.

Although ASTM 1557-03 [21] states that the fiber modulus must also be corrected through compliance correction, the data suggests this may not be accurate for Dyneema fiber. ASTM 1557-03 assumes that the fiber response is linear until failure and corrects the modulus in a similar fashion. However, the stress-strain behavior at low and intermediate rates has a distinct concave downward shape (Figs. 9 and 14) displaying a creep-like behavior. Hence the initial modulus will not be the same as if the fiber was assumed to be linear until failure. For this reason, fiber modulus is not corrected using ASTM 1557-03.

\section{Effect of Fiber Diameter on Failure Strength}

Some studies have noted that restricting fiber diameter to within a certain range is necessary so that the fiber may be gripped using adhesives. This practice may lead to uncharacteristic failure strength values compared to strengths obtained through experimentation on fibers of a wider diameter range. In an effort to understand the effect of fiber diameter on failure strength at each gage length and strain rate, linear correlations (Pearson's r) were performed between the failure strength and fiber diameter with a

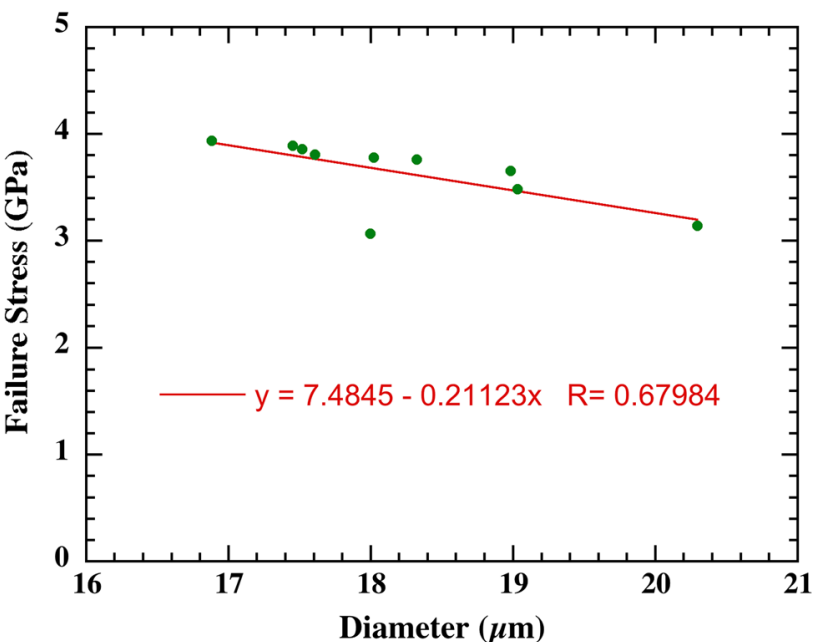

Fig. 13 Dependence of failure strength on fiber diameter. This data set is from quasi-static loading rate with $10 \mathrm{~mm}$ gage length specimens

Table 6 Correlation between failure strength and fiber diameter

\begin{tabular}{llrrrr}
\hline $\begin{array}{l}\text { Gage length } \\
(\mathrm{mm})\end{array}$ & $\begin{array}{l}\text { Strain rate } \\
\left(\mathrm{s}^{-1}\right)\end{array}$ & \multicolumn{1}{l}{ Slope } & Intercept & $\mathrm{r}(8)$ & $\mathrm{p}$ \\
\hline 5 & 0.001 & -0.084 & 5.122 & -0.535 & 0.111 \\
10 & 0.001 & -0.211 & 7.484 & -0.680 & $\mathbf{0 . 0 3 1}$ \\
50 & 0.001 & 0.007 & 3.567 & 0.043 & 0.906 \\
5 & 1 & -0.126 & 6.487 & -0.589 & 0.073 \\
10 & 1 & -0.448 & 12.309 & -0.656 & $\mathbf{0 . 0 4 3}$ \\
50 & 1 & -0.152 & 6.930 & -0.295 & 0.407 \\
5 & 1,000 & 0.048 & 3.337 & 0.122 & 0.692 \\
7 & 1,000 & -0.209 & 7.968 & -0.711 & $\mathbf{0 . 0 3 2}$ \\
10 & 1,000 & -0.106 & 5.988 & -0.487 & 0.153 \\
\hline
\end{tabular}

Values of $\mathrm{p}<0.05$ are in bold which represent a statistically significant negative relationship between diameter and failure strength

significance of $0.05 . \mathrm{N}=10$ for each of the data sets gives a number of degrees of freedom of $8(\mathrm{~N}-2=8)$. A typical plot of failure strength and fiber diameter is shown in Fig. 13. The full results of each of the gage length and strain rates are presented in Table 6.

Previous investigations into the existence of a relationship between fiber diameter and failure strength are mixed, though several studies point to a negative relationship between fiber diameter and failure strength [22-24]. Smook et al. [22] found that the ultimate strength of UHMWPE fibers to be inversely proportional to the square root of fiber diameter. Wagner and Steenbakkers [23] also describe a strong diameter effect on the strength of polyethylene fibers. Bastiaansen posited that these earlier findings existed because the modulus of the fiber was not tightly controlled [25]. When Bastiaansen produced fibers with constant modulus at different diameters, he found no 
relationship between fiber diameter and failure strength of UHMWPE fibers.

Based on the correlations from this study shown in Table 6, we find that three of the nine gage length and strain rate conditions exhibit statistically significant $(p<0.05)$ negative relationships between fiber diameter and failure strength. Because the all fibers in this study were from the same spool, variations in Young's modulus should not exist. It should be noted that Bastiaansen [25] experimented on self-spun fibers having a diameter range of $50-250 \mu \mathrm{m}$, while other studies investigated fibers ranging from 20 to $100 \mu \mathrm{m}$ diameter HiFax 1900 fibers [22] and 22-40 $\mu \mathrm{m}$ diameter Spectra 900 fibers [23]. Dyneema SK76 fibers in this study ranged from 14.5 to $22.3 \mu \mathrm{m}$. It may be possible that past a threshold diameter any correlation between diameter and failure strength no longer exists. The variations of strength with diameter found in this study reinforce the need to conduct tensile strength experiments on a wide diameter range of UHMWPE single fiber samples; the results shown in Table 6 suggest that if only smaller diameter fibers are chosen for experimentation in some cases, the reported failure strengths may be higher than a study on fibers of a larger diameter range. Further studies that include larger sample sets of this specific fiber type would help elucidate the strength-diameter relationship found here.

\section{Shape of Stress-Strain Curves with Respect to Strain Rate}

In general, the stress-strain behavior of UHMWPE fiber is increasingly linear with increasing strain rate $[3,6,9]$. The average behavior of 5 and $10 \mathrm{~mm}$ gage length samples is shown in Fig. 14. The plots represent an average of ten experiments and error bars represent \pm 1 standard of deviation of strength at each strain value. At low rates, the primary deformation mode of UHMWPE fiber is creep [3, 26-30]. Creep was also specifically noted on non-ballistic grades of Dyneema such as SK66 [26] and SK65 [29]. In each case the creep component increases with decreasing strain rate. The increase in linearity of the stress-strain curve is also seen when experiments at different temperatures are conducted [26] suggesting that the mechanism of failure at low temperatures is similar the mechanism of failure at high strain rates.

\section{Summary}

Dyneema SK76 single fibers of diameter $18.22 \pm 1.15 \mu \mathrm{m}$ representing a range of $14.5-22.3 \mu \mathrm{m}$ were successfully gripped and pulled in tension at strain rates of $0.001,1$, and approximately $1,000 \mathrm{~s}^{-1}$ using a gripping technique that had not previously been applied to UHMWPE fibers. The
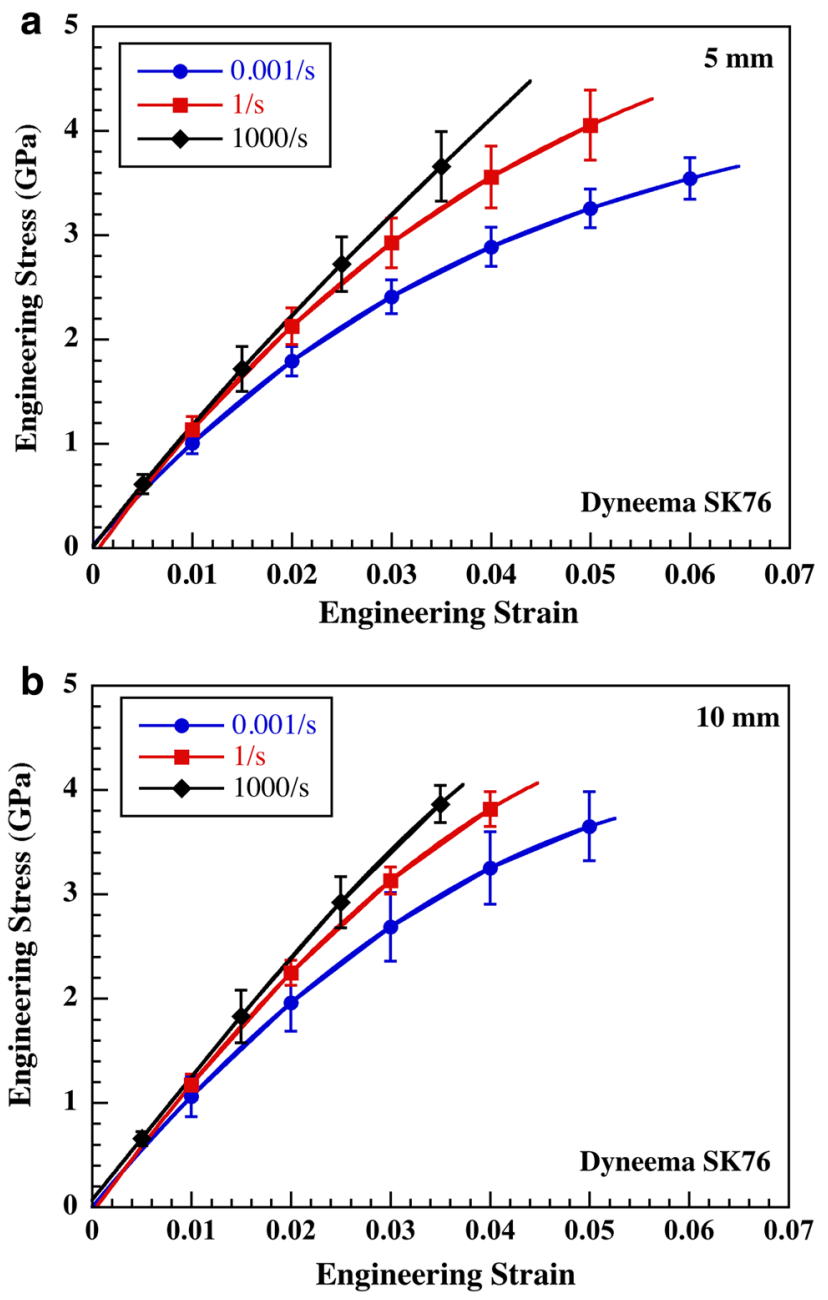

Fig. 14 Stress-strain response at multiple strain rates. Note the increase in linearity for the same gage length with increasing strain rate. The curves in these plots represent the average behavior of ten experiments

gripping technique showed a high amount of success at low and intermediate strain rates and a moderate amount of success at high strain rates. Tensile strength of SK76 fiber increases with strain rate from low rate to intermediate $\left(1 \mathrm{~s}^{-1}\right)$ rate where a plateau in failure strength is reached as seen by no further increase in strength when the strain rate is further increased to $1,000 \mathrm{~s}^{-1}$. The effect of defect distribution was studied by conducting experiments on fibers of multiple gage lengths ranging from 5 to $50 \mathrm{~mm}$. The failure strength of the fiber was not dependent on the gage length of the sample indicating that the distribution of any critical defects in the fiber is at an effective spacing of less than $5 \mathrm{~mm}$. With a sample size of 10 , the linear dependence of fiber diameter on failure strength was found to have a statistically significant $(\mathrm{p}<0.05)$ negative relationship for three of the nine investigated gage lengths and strain rates. Smaller diameter fibers attained higher failure 
stresses in these cases. More experiments are needed to further explore this finding. The shape of the stress-strain curves for SK76 were similar to what other authors have found for UHMWPE fibers where the stress-strain curved increased in linearity with increasing strain rate. This was also noted by authors who investigated UHMWPE at different temperatures, suggesting that the mechanisms of deformation at low temperatures and high strain rates are similar. After the compliance of the experimental apparatus was accounted for by using multiple gage length samples at each rate, the effective failure strain of the Dyneema fiber was similar to manufacturer values for similar fiber types. These results can be used in single fiber based constitutive models for numerical simulation of impact events on soft armor.

Acknowledgments Thanks to Nicole Racine for her help in measuring fibers and conducting experiments.

Conflict of interest The authors declare that they have no conflict of interest.

\section{References}

1. Lin SP, Han JN, Yeh JT, Chang FC, Hsieh KH (2007) Surface modification and physical properties of various UHMWPE fiber reinforced modified epoxy composites. J Appl Polym Sci 104:655-665. doi:10. 1002/app. 25735

2. Umberger PD (2010) Characterization and Response of Thermoplastic Composites and Constituents. Master's Thesis, Virgina Tech

3. Russell BP, Karthikeyan K, Deshpande VS, Fleck NA (2013) The high strain rate response of ultra high molecular weight polyethylene: from fibre to laminate. Int J Impact Eng 60:1-9. doi:10. 1016/j.ijimpeng.2013.03.010

4. Cochron S, Galvez F, Pintor A, Cendon D, Rosello C, SanchezGalvez V (2002) Characterization of fraglight non-woven felt and simulation of FSP's impact in it. Final report for the European Research Office of the US Army, Universidad Politécnica de Madrid, 2002. R\&D 8927-AN-01

5. Hudspeth M, Nie X, Chen W (2012) Dynamic failure of Dyneema SK76 single fibers under biaxial shear/tension. Polymer 53:5568-5574. doi:10.1016/j.polymer.2012.09.020

6. Cansfield D, Ward I, Woods D, Buckley A, Pierce J, Wesley J (1983) Tensile strength of ultra high modulus linear polyethylene filaments. Polym Commun 24:130e1

7. Dyneema Comprehensive Fact Sheet (2008) REF: CIS YA100

8. Spectra Fiber 900,1000, and 2000 (1999) Allied Signal Inc. ASPF-PS9B

9. Schwartz P, Netravali A, Sembach S (1986) Effects of strain rate and gauge length on the failure of ultrahigh strength polyethylene. Text Res J 56(8):502-508. doi:10.1177/004051758605600807

10. Lim J, Zheng JQ, Masters K, Chen W (2010) Mechanical behavior of A265 single fibers. J Mater Sci 45:652-661. doi:10. 1007/978-1-4419-8228-5_20

11. Lim J, Chen W, Zheng JQ (2010) Dynamic small strain measurements of Kevlar ${ }^{\circledR} 129$ single fibers with a miniaturized tension Kolsky bar. Polym Test 29:701-705. doi:10.1016/j.polymertesting.2010.05.012

12. Lim J, Zheng JQ, Masters K, Chen W (2011) Effects of gage length loading rates, and damage on the strength of PPTA fibers. Int J Impact Eng 38:219-227. doi:10.1016/j.ijimpeng.2010.11.009
13. Sanborn B, Weerasooriya T (2014) Quantifying damage at multiple loading rates to Kevlar KM2 fibers due to weaving, finishing, and pre-twist. Int J Impact Eng 71:50-59. doi:10.1016/j. ijimpeng.2014.04.005

14. Kim JH, Heckert AN, Leigh SD, Rhorer RL, Kobayashi H, McDonough WG, Rice KD, Holmes GA (2012) Statistical analysis of PPTA fiber strengths measured under high strain rate condition. Compos Sci Technol 98:93-99. doi:10.1016/j.comps citech.2012.03.021

15. Kim JH, Heckert NA, McDonough WG, Rice KD, Holmes GA (2013) Single fiber tensile properties measured by the Kolsky bar using a direct fiber clamping method. In: Proceedings of Society for Experimental Mechanics Conference. Lombard, IL. doi:10. 1007/978-3-319-00771-7_8

16. Kim JH, Heckert NA, Leigh SD, Kobayashi H, McDonough WG, Rice KD, Holmes GA (2013) Effects of fiber gripping methods on the single fiber tensile test: I. Non-parametric statistical analysis. J Mater Sci 48:3623-3673. doi:10.1007/s10853-013-7142-y

17. Cheng M, Chen W, Weerasooriya T (2005) Mechanical properties of Kevlar KM2 Single fiber. J Eng Mater-T 127:197-203. doi:10.1115/1.1857937

18. Prevorsek D, Chin H, Kwon Y, Field J (1991) Strain rate effects in ultrastrong polyethylene fibers and composites. In: Ludwig $\mathrm{R}$ (ed) Proceedings of the fiber society 50th anniversary technical conference, vol 47. Princeton, NJ, USA p. 45e66

19. Wagner HD, Aronhime J, Marom G (1990) Dependence of the tensile strength of pitch-based carbon and para-aramid fibres on the rate of strain. P Roy Soc Lond A Mat 428(1875):493e510. doi:10.1098/rspa.1990.0045

20. Govaert LE, Peijs T (1995) Tensile strength and work of fracture of oriented polyethylene fibre. Polymer 36(23):4425-4431. doi:10.1016/0032-3861(95)96848-3

21. ASTM-C-1557-03 (2008) Standard Test Method for Tensile Strength and Young's Modulus of Fibers. Annu Book ASTM Stand. doi:10.1520/c1557-03r08

22. Smook J, Hamersma W, Pennings AJJ (1984) The fracture process of ultra-high strength polyethylene fibres. J Mater Sci 19(4):1359-1373. doi:10.1007/BF01120049

23. Wagner HD, Steenbakker LW (1989) Stochastic strength and size effect in ultra-high strength polyethylene fibres. Phil Mag Lett 59:77-85. doi:10.1080/09500838908214780

24. Amornsakchai T, Cansfield DLM, Jawad SA, Pollard G, Ward IM (1993) The relation between filament diameter and fracture strength for ultra-high-modulus-polyethylene fibres. J Mater Sci 28(6):1689-1698. doi:10.1007/bf00363369

25. Bastiaansen CWM (1992) Tensile strength of solution-spun ultradrawn ultra-high molecular weight polyethylene fibres: 1 . Influence of fibre diameter. Polymer 33(8):1649-1652. doi:10.1016/ 0032-3861(92)91061-6

26. Govaert LE, Bastiaansen CWM, Leblans PJR (1993) Stress-strain analysis of oriented polyethylene. Polymer 34(3):534-540. doi:10.1016/0032-3861(93)90546-m

27. Wilding MA, Ward IM (1978) Tensile creep and recovery in ultra-high modulus linear polyethylenes. Polymer 19:969-976. doi:10.1016/0032-3861(78)90208-2

28. Wilding MA, Ward IM (1978) Creep and recovery in ultra-high modulus polyethylene. Polymer 22:870-876. doi:10.1007/ bf00553588

29. Wilding MA, Ward IM (1984) Creep and Stress-relaxation in ultra-high modulus linear polyethylene. J Mater Sci 19:629-636. doi:10.1007/bf00553588

30. Liu X, Yu W (2005) Evaluation of the tensile properties and thermal stability of ultrahigh-molecular-weight polyethylene fibers. J Appl Polym Sci 97:310-315. doi:10.1002/app.21720 